Results Children and families unanimously placed a high value on the quality of the event in terms of:

- Therapeutic value

- Facilitating dialogue which acknowledged the loss of the person who had died

- Making meaningful memories

- Reducing the sense of isolation within families

Staff and volunteer experience was enriched through their involvement.

\section{P144 MEET MR FOUL! AN INNOVATIVE APPROACH TO GET TO THE HEART OF DISTRESS: A THERAPEUTIC TOOL TO WORK WITH PATIENTS IN 'EXTERNALISING' ILLNESS, SYMPTOMS AND THEIR CONSEQUENCES}

Kimberley McLaughlin. The Hospice of St Francis, Berkhamsted, UK

10.1136/bmjspcare-2013-000591.166

Context Introduced to the field of family therapy in the 1980s, 'externalising' practice aims to enable people to realise that they and the problem are not the same thing. Externalising the problem encourages a separation from the problem - 'the person is not the problem, the problem is the problem' $\square$ (White 2007:9). A space is created between the person and whatever is troubling them. Often problems become 'internalised'; with patients seeing illness as something wrong with them, that they or something about them is problematic.

In Practice Externalising helps us to shift self-blame. A patient living with Parkinson's disease said 'I'm so pathetic, so incompetent and such a burden...'. Externalising questions helped to reshape the relationship with Parkinson's e.g. 'How long has Parkinson's been influencing you?', 'What does Parkinson's tell you about yourself?', 'When is Parkinson's not so strong?'. Questions enabled collaborative exploration of the effects and tactics of problems and helped to reduce their influence.

This encouraged separation from the problem, the patient began to see her symptoms as external to themself. Contributing to this process was her renaming Parkinson's as 'Mr Foul Disease'. Self-blame decreased and 'Mr Foul' became more manageable and less powerful. A sense of relief was experienced as the patient realised she was not the problem and became more able to reconnect stories about herself as 'capable, insightful and determined'.

Discussion Externalising conversations can be flexible, creative and encourage patients to use their own problem-solving strategies, skills. They provide palliative practitioners with a tool, which positions them alongside their patients' problems, jointly exploring of new ways of relating to illness and symptoms rather than a position of expertise.

\section{P145 LIFE STORIES: REBUILDING SELF ESTEEM THROUGH SHARING AND RECORDING BIOGRAPHICAL STORIES}

Doreen Pattenson, Miranda Quinney. The Peace Hospice, Watford, United Kingdom

\subsection{6/bmjspcare-2013-000591.167}

Introduction In 2012 we were approached by a local storyteller. We experimented with a simple programme, offering patients the opportunity to tell their stories on an informal basis and produced a series of summaries of the stories they told. We are now piloting a closed group version of Life Stories offering a $5-6$ week course of story sharing sessions to day patients and patients in the community. The results observed to date have been overwhelming - we want to share these with you.

Aims The aims of Life Stories are to provide a space for reflection and story telling for patients who are low in mood or anxious.

Methods The weekly 1.5 hour sessions are facilitated by the storyteller and attended by the social worker. Each session is structured using common life experiences, e.g. seasons, senses, celebrations. Using a mix of group, individual and pair work, all participants are invited to explore the theme and its meaning for them before sharing a related life story with a session partner. Next the stories are shared out loud with the whole group giving the facilitator a chance to record them all.

Results The reaction of the patients and their families to this experience is very positive; patients visibly brighten and do not want to leave. They report enhanced feelings of wellbeing, happiness and a generally improved quality of life. A family member reported: "my mother is talking again and painting again - thank you".

Conclusion Positive feedback from patients, their carers and hospice staff suggest that Life Stories workshops should be made available as part of a patient's individual care plan and be a regular part of the hospice day services.

\section{P146 WHO MATTERS TO ME? - USING ECOMAPS IN PATIENT ASSESSMENT \& CARE}

Bernadette Gallagher. St Joseph's Hospice, London, UK

10.1136/bmjspcare-2013-000591.168

When doing good quality assessments for patients at St Joseph's Hospice it was recognised that genograms did not tell the whole story - so I looked to Ecomaps

Dr Ann Hartmann developed the ecomap as part of her social work practice in 1975 . Initially it was used as a tool to show family life but Dr Hartmann then recognised that it was a useful tool to show a diagrammatic picture of a person's life and helped clients view their situation from an outside perspective.

The term eco is derived from the Greek ecology - the pattern of relationships between plants, animals $\&$ people to each other $\&$ their surroundings.

The ecomap is a graphical representation of an individual or family and their interaction with other people \& their environment. It is underpinned by the Systems Theory as described by Pincus \& Minahan (1973)

- Informal Systems e.g. family, friends \& neighbours. Providing emotional support $\&$ advice.

- Formal systems e.g. clubs, societies \& other groups that can provide support.

- Public systems e.g. hospitals, schools \& local government.

The systems theory is useful in looking at an individual's systems (their support network) to recognise \& promote strengths and to sustain relationships that are under strain, it is at the heart of person centred planning. It is therefore used for assessment, planning $\&$ intervention.

The ecomap is as individual as the person and a positive is that it can show spiritual domains that are very important to the person to help cope with illness this can include transpersonal beings (angels, demons, ancestors).

Ecomaps are now included in St. Joseph's Hospice Core Assessments \& each patient's ecomap will be displayed in our 
Multi-Disciplinary meetings to ensure that the patient \& their world are kept the centre of our focus.

\section{P147 THE SOCIAL UNIVERSE - GETTING BEYOND GENOGRAMS TO MAP PATIENT NETWORKS}

Ros Taylor. Hospice of St Francis, Berkhamsted, United Kingdom

\subsection{6/bmjspcare-2013-000591.169}

Context Forecasts of profound demographic change and diminishing health care resources together with patient preferences to be cared for at home, suggest that future community support will need to be shaped very differently, identifying new sources of resilience.

Networks around people could be harnessed to offer social and practical support, and in many cases healthcare support. This underpins the public health approach to palliative care.

Proposal There is a presumption by practitioners that the traditional genogram describes the support network - this may be the case but it seems important to understand a more inclusive and interactive network, the strength and weakness of the links, potential for change and the conversations needed to facilitate strengthening of these links. Network 'poor' patients will also be identified.

The Social Universe Tool (based on Macy's support map)

The palliative patient is given a blank sheet with their name in the centre and is asked to map all those people in their 'universe'.

These may include :

Relatives, friends and neighbours

Facebook friends

Work colleagues

Members of groups or clubs

The thickness of arrows drawn in both directions between the patient and each name determines the strength of support given and received.

Reflections on conversations that need to happen to strengthen key relationships are formulated together

For example - there may be a thin line from a friend towards the patient - the patient feels this friend would like to help more - what conversation needs to happen to strengthen the universe ?

Initial results The Social Universe map has been piloted to look at acceptability and usability with 20 patients of different ages and backgrounds.

All patients have found it a creative and relevant way to understand their networks and to think about tactics to strengthen relationships!

Next Steps Formal evaluation with professionals and patients, followed by training of hospice practitioners to launch as part of routine holistic assessment.

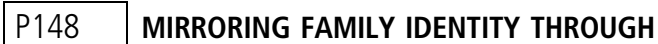 DOCUMENTARY FILMMAKING: INNOVATIVE WAYS OF WORKING WITH FAMILIES IN A HOSPICE SETTING.}

Haraldsdottir Erna, Amy Hardie Kendall Maril. Strathcarron Hospice, Denny, Stirlingshire, Primary Palliative Care Research Group, The University of Edinburgh

\subsection{6/bmjspcare-2013-000591.170}

Background Expressive arts are increasingly being used within Palliative Care (PC) to add to desired outcomes. We wished to develop these techniques working with families in a hospice setting.

Aims To explore \& evaluate the use of documentary film making techniques in PC to support families and patients.

Method A film artist, resident in a hospice for a year, worked with staff, patients \& families using \& teaching camera $\&$ editing skills to produce documentary films. They took part in a series of qualitative interviews to explore their experience. 30 interviews were completed, transcribed verbatim \& entered into Nvivo 7 for thematic analysis.

Results 12 families made films in an iterative process that included reflective listening $\&$ screening, which this paper will analyse as 'mirroring'. These films had various purposes such as 'legacies', made for those facing bereavement, 'portraits' allowing the family to see \& take stock of their life stories; 'play spaces', where family members could express the parts of themselves that may get submerged in the problem-solving ethos of dealing with illness.

Conclusion The families found making a documentary film about their life brought them together, allowing them to 'tell their story' \& leave a legacy of family archive. Patients reported they enjoyed specifically seeing the closeness between the family members \& the positive functioning of the family reflected in the film. The legacy aspect of the film is of particular importance to patients with young children. Documentary film goes further than the traditional 'memory box', it captures the day-today life of the family together reflecting the relationship the patient has with his/her family as well as mirroring the family identity. Working with a film artist in a hospice has equipped the staff with new technical knowledge \& a ground-breaking documentary intervention to use with families in a PC setting.

Funding : Creative Scotland

\section{P149 DISCOURSE ON METHOD: TESTING A METHODOLOGY FOR USE IN UNDERSTANDING WHAT SPIRITUAL CARE SPECIALISTS MEAN BY 'SPIRITUAL NEED'}

Steve Nolan. Princess Alice Hospice, Esher, UK

10.1136/bmjspcare-2013-000591.171

Aim To test a methodology for use in understanding what is meant by 'spiritual need'

Background Nurses are required routinely to conduct spiritual assessments (NMC 2010). Yet, despite a growing literature around spiritual assessment (McSherry \& Ross 2010; Holloway et al 2011), knowledge about what constitutes spiritual needs remains limited. Without this knowledge, nurses are ill-equipped to make their assessments (McSherry \& Jamieson 2011). The methodology is intended to be used in a lager study aimed at building a spiritual need typology.

Method The pilot study - an interpretive study using a form of discourse analysis - worked with 9 spiritual care specialists, each of whom shared, in depth, one encounter with a person they considered had been in 'spiritual need'. Working in focus groups and using semi-structured questions, the method aimed to:

1. gather narrative accounts about the experience of people in spiritual need;

2. generate descriptive vocabulary articulating those experiences.

Participants orally described their encounter, which they then documented on a specially designed form. Participants next 